\title{
Hazards to Aircraft Crews, Passengers, and Equipment from Thunderstorm-Generated X-rays and Gamma-Rays
}

\author{
Karl D. Stephan ${ }^{1}$ and Mikhail L. Shmatov ${ }^{2, *(D)}$ \\ 1 Ingram School of Engineering, Texas State University, San Marcos, TX 78666, USA; kdstephan@txstate.edu \\ 2 Division of Solid State Electronics, Ioffe Institute, 194021 St. Petersburg, Russia \\ * Correspondence: m.shmatov@mail.ioffe.ru
}

check for updates

Citation: Stephan, K.D.; Shmatov, M.L. Hazards to Aircraft Crews, Passengers, and Equipment from Thunderstorm-Generated X-rays and Gamma-Rays. Radiation 2021, 1, 162-173. https://doi.org/ $10.3390 /$ radiation 1030015

Academic Editor: Leonardo Abbene

Received: 24 May 2021

Accepted: 25 June 2021

Published: 29 June 2021

Publisher's Note: MDPI stays neutral with regard to jurisdictional claims in published maps and institutional affiliations.

Copyright: (c) 2021 by the authors. Licensee MDPI, Basel, Switzerland. This article is an open access article distributed under the terms and conditions of the Creative Commons Attribution (CC BY) license (https:// creativecommons.org/licenses/by/ $4.0 /)$.
Simple Summary: Until recently, it was not known that thunderstorms generate $\mathrm{X}$-rays and gammarays, which are high-energy forms of ionizing radiation that can cause both physical harm to living organisms and damage to electronics. Over the last four decades, we have learned that thunderstorms produce $\mathrm{X}$-rays during lightning strikes and also generate gamma-rays by processes that are not yet completely understood. This paper examines what is known about the sources of ionizing radiation associated with thunderstorms with a view to evaluating the possible hazards to aircraft crews, passengers, and equipment.

Abstract: Both observational and theoretical research in the area of atmospheric high-energy physics since about 1980 has revealed that thunderstorms produce $\mathrm{X}$-rays and gamma-rays into the $\mathrm{MeV}$ region by a number of mechanisms. While the nature of these mechanisms is still an area of active research, enough observational and theoretical data exists to permit an evaluation of hazards presented by ionizing radiation from thunderstorms to aircraft crew, passengers, and equipment. In this paper, we use data from existing studies to evaluate these hazards in a quantitative way. We find that hazards to humans are generally low, although with the possibility of an isolated rare incident giving rise to enough radiation dose to produce noticeable symptoms. On the other hand, unshielded computer memory chips in avionics systems stand a small but non-zero chance of severe damage from thunderstorm-generated radiation and would not leave easily detectable traces of the occurrence. Should a rare phenomenon called ball lightning occur near or within an aircraft, the possibility exists of substantial damage to both equipment and personnel. Overall, radiation hazards from thunderstorms appear to be low, but should be considered and investigated with radiation monitoring equipment on sample flights.

Keywords: radiation; lightning; thunderstorm; X-rays; gamma-rays; ball lightning

\section{Introduction}

Since the beginning of the aviation industry, the obvious hazards to aircraft presented by thunderstorms have been a major concern: unpredictable and violent winds, impairment of visibility by clouds, and heavy rain, hail, and lightning. Pilots therefore avoid thunderstorms whenever possible. While radar, improved weather prediction, and other aids have made it easier for aircraft to avoid the more obvious hazards presented by thunderstorms, lightning continues to be one of the least predictable aspects of thunderstorm activity. Although rare, there are documented cases of long intra-cloud flashes travelling for hundreds of miles into clear-air regions [1]. Therefore, the possibility of either a direct lightning strike or a flash in the immediate vicinity of an aircraft cannot be completely disregarded even if the closest active thunderstorm is many miles away.

During the long era of all-metal airframe construction, the hazards of direct lightning strikes were not of great concern, as the aluminum skin used provided an excellent Faraday cage shield against most of the deleterious effects of lightning on personnel and equipment 
on board. With the advent in aircraft construction of composite materials that are not inherently conductive, lightning protection has had to be designed into the aircraft by means of conductive material embedded into the composite explicitly for lightning protection. The consensus is that these measures are at least as effective as the old all-metal airframes were in preventing lightning damage.

The purpose of this paper is to draw additional attention to a hitherto almost unexamined possible hazard presented by ordinary and ball lightning to air travelers: injuries and damage due to invisible ionizing radiation, primarily $\mathrm{X}$-rays and gamma-rays. A short review of the current knowledge of the high-energy physics of lightning and thunderstorms follows.

\section{High-Energy Physics of Lightning}

\subsection{X-rays from Lightning}

Although C. T. R. Wilson predicted as long ago as 1925 [2] that the strong electric fields in thunderstorms may be capable of producing highly accelerated electrons (Wilson used the term "beta particles") and consequently high-energy photons, reliable confirmation of this prediction and the establishing of some of the conditions corresponding to its realization had to await the development of systems both sensitive enough to detect such radiation and, in some situations, sophisticated enough to establish the correlation or anticorrelation of the radiation in time with the lightning strikes producing or terminating this (see, e.g., [3-5] and bibliographies therein). The ever-present cosmic-ray background and other factors made it difficult to obtain unambiguous data on high-energy electrons and photons produced by thunderstorms. According to [5], "The modern era of observations of high-energy radiation began with the airplane flights of Parks and collaborators from the University of Washington (Parks et al. 1981; McCarthy and Parks 1985)" (we cite papers by Parks et al. (1981) and McCarthy and Parks (1985) as [6] and [7], respectively). Experiments by Moore et al. in 2001 [8] and Dwyer et al. in 2003 [9] provided incontrovertible evidence that many ordinary and rocket-triggered lightning strikes are accompanied by energetic radiation ranging from the soft $X$-ray region $(10 \mathrm{keV})$ to the gamma-ray region $(>1 \mathrm{MeV})$. As with lightning discharges themselves, the accompanying ionizing radiation occurs in short bursts lasting a few milliseconds at most. The total dosage due to exposure of the human body to any such radiation was generally not regarded as worthy of concern compared to the more serious harm that lightning can cause directly to the human body, as even hard X-rays are greatly attenuated in passing through several tens of meters or more of atmospheric-pressure air. However, it is worth noting that some observational data allow us to assume that in very rare situations high-energy photons from lightning can be dangerous for nearby humans (see, e.g., [4]).

\subsection{Terrestrial Gamma-Ray Flashes}

The phenomenon known as terrestrial gamma-ray flashes (TGFs) consists of X-rays and gamma-rays produced by lightning discharges. Terrestrial gamma-ray flashes were discovered in 1994 by satellite-based detectors designed to observe celestial sources of gamma-rays [10]. TGFs last up to a few milliseconds and their photons have energies ranging up to about $100 \mathrm{MeV}$ [11]. At present, it is not known exactly what structure(s) in the thunderstorm produce TGFs, although TGFs detected from satellites appear to be associated with intra-cloud lightning flashes at altitudes of $10-20 \mathrm{~km}$. Compared to the common low-energy $\mathrm{X}$-rays produced in direct association with lightning strikes, TGFs occur relatively infrequently. Tavani et al. [11] estimate that one TGF takes place for about every 10,000 lightning discharges. According to Smith et al. [12] and Dwyer et al. [5], TGFs are associated with $0.1-1 \%$ of lightning flashes. 


\subsection{Gamma-Ray Glows and Secondary Emission of High-Energy Photons Due to Photonuclear Reactions}

One more high-energy phenomenon has been discovered to be associated with thunderstorms. It is often referred to as "gamma-ray glows" [5,13-18] or "thunderstorm ground enhancements" $[19,20]$, although no single term has been agreed on yet to describe it (see, e.g., [4,21-25]). Enoto et al. [25] use the term " $\gamma$-ray glow" only to describe "bremsstrahlung radiation from electrons accelerated in thunderclouds". They distinguish between this and a different type of emission which lasts for up to a minute and arises due to production of $\beta^{+}$-active isotopes by a short, strong gamma-ray flash, initiating several photonuclear reactions, in particular, ${ }^{14} \mathrm{~N}+\gamma \rightarrow{ }^{13} \mathrm{~N}+\mathrm{n}$, and the subsequent annihilation of positrons emitted by these isotopes. They term the latter emission "prolonged line emission." The term "prolonged emission" can be considered as a universal one describing any flux of high-energy photons not associated with rain washout of radioactive isotopes (see, e.g., $[15-18,20,21,23,25])$, with a duration of about one second or longer.

Gamma-ray fluxes, described as gamma-ray glows, etc., can last from seconds to minutes, and can produce gamma-ray photons with numbers exceeding the normal background level in some spectral ranges at least by one to two decades, while situations when the intensity of the glow is of the order of $10 \%$ of the background are also described [4,5,13-21,26,27]. In principle, the generation of several subsequent and/or time-overlapping glows seems to be possible (see, e.g., $[20,28])$. In some situations, such processes can be interpreted as the generation of one glow with a relatively long duration.

The photonuclear reactions mentioned above are also accompanied by the emission of high-energy photons due to capture of about $4 \%$ of neutrons by atmospheric ${ }^{14} \mathrm{~N}$, etc. The temporal dependence of this emission can be described as decay with a typical time which is about $40-60 \mathrm{~ms}$ at relatively low altitudes $[25,29]$ and increases with altitude due to a decrease in air density [29].

The detection of gamma-ray glows by ground-based or roof-mounted equipment is hampered by the absorption and scattering of photons by air, although this problem is reduced if observations are made at high-altitude mountain observatories or of thunderstorms with low-altitude charge-containing regions $[4,5,13,14,17-21,23,26-28,30,31]$. However, the altitudes at which commercial jet aircraft fly and the possibility of relatively short distances between the main region of the emission of high-energy photons and the aircraft mean that the aircraft are much less protected from such radiation by the air than is the case at ground level. It should be emphasized that there are several different assumptions about the physical nature of gamma-ray glows (see, e.g., [12,15,18,20,22-24,26,28,29] and bibliographies therein). According to one author, some gamma-ray glows are generated by ball lightning $[22,24,28,31]$. This assumption is considered below and probably corresponds to the highest expected danger of gamma-ray glows and phenomena accompanying them.

\subsection{Physical Mechanisms of TGFs and Related Phenomena}

Although many details are still lacking, the general mechanisms by which thunderstorms produce $\mathrm{X}$-rays and gamma-rays in some situations are more or less clear. In the case of lightning, high electric fields at the tip of a propagating leader and/or its streamers accelerate electrons to energies which are sufficient for the production of high-energy photons of bremsstrahlung radiation. In the case of some TGFs, it is fairly certain that relativistic runaway electron avalanches (RREAs) are responsible [32], and RREAs can also be involved in X-rays produced by lightning. Above a threshold electric-field strength of about $284 \mathrm{kV} / \mathrm{m}$ at sea level, sufficiently fast free electrons in the atmosphere gain more energy from the field than they lose to collisions, on average, and so they "run away," giving rise to an avalanche of electrons which can reach relativistic energies, as long as the region where the electric field strength exceeds the threshold value is long enough. Such relativistic electrons can also produce positrons, which because of their opposite charge are accelerated toward the origin of the electron avalanche and further contribute to the avalanche's buildup. Simulations of RREAs have been shown to produce gamma-ray 
emissions very similar to those measured in some TGFs, and RREAs may also be implicated in gamma-ray glows, although the origin of such glows is still under discussion.

The main uncertainties surrounding these phenomena concern the exact shape and extent of the high-energy electron and positron beams produced by RREAs. Estimates of the beam diameter range from $2 \mathrm{~m}$ to $100 \mathrm{~m}$ and more, and the length depends essentially on the details of the electric field producing the avalanche. Nevertheless, it is clear that RREAs are large enough to have significant potential for interacting with an aircraft, especially if the aircraft is at an altitude where this phenomenon takes place.

Some TGFs have hard spectra, i.e., significant spectral densities at photon energies of several tens of MeV [33-36]. The initial acceleration of electrons of such TGFs occurs in the regime called cold or thermal runaway (see, e.g., [5,33-35,37,38]). In this regime, an electron acquires a high kinetic energy $\varepsilon_{\mathrm{k}}$ at any initial value of energy $[5,33-35,37,38]$. The minimum or, in other words, critical electric field strength $E_{\mathrm{cr}}$, necessary for the realization of the regime is about one hundred times greater than the threshold value mentioned above. For example, according to Babich [38], at standard conditions $\mathrm{E}_{\mathrm{cr}} \sim 40.6 \mathrm{MV} / \mathrm{m}$. Several models of initial acceleration of TGFs with hard spectra due to cold runaway were proposed (see, e.g., [34-36] and bibliographies therein). These models correspond to rather compact regions of formation of the fluxes of high-energy electrons and, as a result, to a relatively high radiation hazard of some TGFs [36]. Differences between the models lead to a significant difference in the angular distributions of the fluxes of high-energy electrons and photons [36].

Kutsyk et al. [39] described one more scenario of the generation of high-energy photons by lightning. This scenario involves the transfer of a high positive potential to the airplane by a positive lightning leader, and subsequent discharge with the generation of runaway electrons and generation of bremsstrahlung radiation by electrons in metallic regions of the aircraft [39]. The realization of such a scenario is extremely dangerous due to the high efficiency of the last process [39]; see also below.

\section{Hazards to Aircraft from TGFs and Positive Leader Strikes}

As commercial aircraft fly at altitudes that are comparable to the estimated heights at which some of the TGFs and gamma-ray glows originate, there is a concern that both airborne equipment and personnel could be exposed to deleterious amounts of ionizing radiation if the aircraft happens to encounter a beam of high-energy electrons or gamma-rays produced when these electrons lose their energy in the form of photons through collisions and bremsstrahlung radiation. Because the details of damage differ significantly in the case of hazards to personnel and hazards to equipment, we will deal with them separately.

\subsection{Hazards to Aircraft Personnel}

Dwyer et al. [40] have written a detailed study estimating the potential for radiationinduced injuries to the human body if an aircraft encounters a flux of high-energy electrons and gamma-rays, such as those measured in observations and modeled in theoretical calculations of RREAs in thunderstorms. They examined both the radiation that would be emitted from a lightning leader aimed at the aircraft and from a TGF occurring in the vicinity of the aircraft. As Dwyer et al. [40] point out, a typical commercial airliner is struck by lightning an average of once or twice a year, so such incidents are common enough to be considered seriously.

The unit used for quantifying human exposure to penetrating ionizing radiation is the sievert (Sv). The sievert is proportional to a physical quantity called the gray (Gy), which is in turn equal to one joule of radiation energy deposited per kilogram. The constant of proportionality $\mathrm{Q}$ is a dimensionless number that takes into account the biological activity of the type of radiation under consideration. For the $\mathrm{X}$-rays and gamma-rays considered by Dwyer et al. [40], $Q=1$, which makes the dosage in sieverts and grays numerically equal.

As the diameter of the avalanche beam involved in lightning X-rays and TGFs is so uncertain, Dwyer et al. [40] considered beam diameters ranging from $2 \mathrm{~m}$ to $2000 \mathrm{~m}$. For 
lightning-generated radiation, the dose received from a beam directed at a human body in an aircraft exceeded the limit of $1 \mathrm{mSv}$ recommended by regulatory agencies for the general civilian population when the electrons were concentrated into a beam with a diameter of about $700 \mathrm{~m}$ or less. The more intense TGF beam crosses the same threshold at a larger diameter of about $1350 \mathrm{~m}$. At a beam diameter of about $50 \mathrm{~m}$, the TGF beam resulted in a dose of almost $1 \mathrm{~Sv}$, which is the threshold above which symptoms of mild radiation sickness might appear.

Dwyer et al. [40] concluded that although the chances of any one commercial flight encountering such a radiation event were small, the large number of commercial airline passenger-miles per year and the known frequency of lightning strikes to aircraft mean that some passengers (and especially crew members who fly frequently) may have received many times the recommended maximum radiation dosage of $1 \mathrm{mSv}$ during their time in the air, due to either lightning-produced X-rays or a nearby TGF. These predictions have yet to be verified by onboard radiation monitoring experiments, but such investigations might prove extremely informative, both from the practical view of quantifying this hitherto unsuspected hazard and from the viewpoint of fundamental physical research.

Kutsyk et al. [39] mentioned the danger of ionizing radiation generated by lightning leaders for electronic equipment, crew, and passengers, and estimated the dose corresponding to the strike of a positive leader to an airplane as 10-100 mSv. They also mentioned that according to the requirements of the Rosatom State Corporation (a Russian agency concerned with nuclear reactors, weapons, and safety), the maximum allowed dose is $0.2 \mathrm{mSv}$ per year.

Torii et al. [4] published observational data according to which "dose increases measured by thermoluminescent dosimeters (TLDs) exposed during a period including a lightning flash were up to about $0.1 \mathrm{mGy}^{\prime \prime}$. The data were obtained in and around buildings of the nuclear power plant exploiting the Fast Breeder Reactor "Monju" in the coastal area of the Hokuriku district, Japan, on 28 January 281997 [4]. The data from [4,22-25] allow us to assume that the main fractions of the aforementioned dose increases were associated with TGF(s) which occurred at a relatively low altitude, while the rest of the increases corresponded to prolonged emission and could be associated with the formation of ball lightning and/or the generation of $\beta^{+}$-active isotopes and/or other effect(s) (time resolution of the equipment described in [4] did not provide the possibility to detect a TGF directly). The fact that the minimum distances between the TLDs and the main region(s) of the generation of the high-energy photons were not established can be considered as an additional factor indicating the potential biological hazard of high-energy photons of atmospheric origin, in particular of those generated by TGFs.

Several statements made by Prof. David Smith about the potential radiation hazard of TGFs are contained in [17]. One of them is the following: "in the worst case scenario, you could have people walking off the plane with visible signs of radiation sickness" [17]. Some aviation safety problems related to electrons, accelerated in atmospheric electric fields, and high-energy photons, generated by these electrons, were briefly discussed by Meier et al. [41]. In particular, Meier et al. [41] have mentioned the fact that pilots of commercial aircraft "try to avoid thunderstorms" and consider this as a reason to doubt the applicability of the dose assessment of Dwyer et al. [40] for commercial aircraft.

\subsection{Hazards to Aircraft Equipment}

An investigation of hazards posed by TGFs to aircraft was also undertaken by Tavani et al. [11] but instead of investigating the effects on people, [11] addressed the question of potential damage to aircraft avionics. Modern semiconductor-based electronics contain numerous radiation-sensitive components, such as static random-access memories (SRAMs), which if not specifically radiation-hardened can sustain either temporary or permanent damage from ionizing and other types of radiation. Their paper considered the following damage mechanisms. 
Short intense bursts of X-rays and gamma-rays can cause charges to appear in unexpected places in circuits, which then leads to bit errors, latchup, or even burnout. Most electronic systems are protected against a single isolated bit error that can be caused by a stray cosmic ray, for example. However, most designs do not anticipate the simultaneous appearance of many such errors in widely separated locations, as would occur with a sufficiently intense TGF.

In addition to electromagnetic effects related to high-energy photons, electrons, and positrons, Tavani et al. [11] studied those of neutrons produced by gamma-rays in excess of $15 \mathrm{MeV}$, which could be present as TGFs have been measured with energies as high as $100 \mathrm{MeV}$. In the situations under consideration, the neutrons originate as photoneutrons from collisions between high-energy gamma-rays and aluminum nuclei in the airframe. When a high-energy neutron collides with a nucleus in a small MOS transistor in an SRAM device, the positively-charged nucleus leaves a path of ionization in its wake that is large enough to change the state of the memory cell in some cases [42]. Due to this effect, the neutron flux resulting from a TGF may play a more important role in avionics damage than any direct electromagnetic effects due to high-energy electrons or the gamma-rays resulting from them.

Tavani et al. [11] concluded that for TGF beams with fluences of more than $10^{17}$ radiating electrons involved, a beam of $3 \mathrm{~m}$ diameter could cause significant avionics damage. For beams involving as many as $10^{19}$ electrons (larger than the typical TGF but still possible), a beam of $30 \mathrm{~m}$ diameter could still cause multiple SRAM failures and consequent severe disruption of avionics functionality. While no known accidents have yet been traced to this cause, the work of Tavani et al. [11] shows that modern aircraft may be unexpectedly vulnerable to TGFs in a way that would be very difficult to detect or investigate after the fact.

While these theoretical studies have made it clear that TGFs and related ionizing radiation due to thunderstorms may pose hitherto unexpected hazards to aircraft personnel and equipment, no known injuries or deaths have been attributed to such causes. On the other hand, there have been several documented cases in which the rare phenomenon termed ball lightning has caused such casualties, and there are reasons to believe that ball lightning should also be considered to be hazardous for air travelers, as we will describe next.

\section{Ball Lightning and Its Hazards}

Despite centuries of observations and decades of scientific attention to this thunderstormrelated phenomenon, our knowledge of ball lightning is limited by the scarcity of observations compared to those of ordinary lightning and our inability to reproduce a phenomenon in the laboratory that resembles naturally-occurring ball lightning in essential respects. Rakov and Uman [3] have provided a succinct description of the essential characteristics common to most authentic ball-lightning sightings, among which are the following: (1) it is usually associated with thunderstorms or cloud-to-ground lightning; (2) it is usually seen as a sphere $10-30 \mathrm{~cm}$ in diameter, self-luminous with the intensity of a domestic light bulb, and keeps these characteristics more or less constantly during its lifetime; (3) it can appear either in open air or enclosed spaces such as houses and metal-skin aircraft; (4) it moves mostly horizontally in a manner that is inconsistent with a hot gas. Although it is rare for ball lightning to cause damage or injury, such cases are not unknown, and their details may hold important clues both to the nature of the phenomenon and the kinds of injuries and damage it can cause.

\subsection{Ball Lightning Casualties}

The literature on ball lightning is vast, and the interested reader is referred to review articles [31,43,44], books [45-48], and a book chapter [49] for further general background and extensive compilations of eyewitness accounts. From the accounts of injuries and deaths related to ball lightning, we have drawn the following incidents as particularly relevant to the questions of hazards that ball lightning presents to aircraft and the possibility 
of checking the assumption about the radiation hazard of some ball lightning by means of additional investigation of accidents.

One of the most well-documented cases of ball lightning causing injury was reported in the Annals of Plastic Surgery [50] in 2003. A young man, his wife, and his five-year-old daughter were in a room heated by an open wood fire in a fireplace in rural Belgium. The man was adjusting wood and papers in the fireplace. A ball lightning object emerged from the fireplace, pushed the man $3 \mathrm{~m}$, turned, and struck the man's daughter, who was seated at a table. It then went under the table, into the kitchen, through a washroom, and out the back door, leaving small fires and blackened spots in its path. The man sustained second-degree burn wounds on the cheekbone and hand (total body surface area $4 \%$ ). The daughter sustained second- and third-degree burns on the left neck, both upper arms, and back (total body surface area 30\%), and was treated for more than a month before recovering completely. The entire event was witnessed both by the daughter and her mother nearby, while the father lost consciousness briefly. This incident shows that ball lightning can contain enough energy in some form to produce substantial burns on the human body. From the viewpoint of aviation safety, the fact that the man lost consciousness is very important. It is evident that loss of consciousness of pilot(s) can result in a crash.

In 2018, doctors reported a ball-lightning injury to a young boy [51] in which the skin of his abdomen was burned in a Lichtenberg-figure pattern. The burn site corresponded to the location at which the ball lightning object approached within $1 \mathrm{~m}$ of his body after emerging from a fireplace. The boy recovered quickly from the resulting first-degree burns. The fractal Lichtenberg figures are characteristic of electrical discharges over semiinsulating surfaces such as dry skin, and the presence of such a figure in the burn marks indicates that the injury was probably electrical in nature.

The injuries and other consequences of the influence of ball lightning on humans are also described in several other papers published in medical journals (see, e.g., [52-54]) and other works (see, e.g., [31,44,49,55-57]). In particular [54] contains a report about the direct contact of ball lightning with the right face of a 41-year-old woman who later suffered from memory loss, irritability, and depression.

To the best of our knowledge, [52] is the only paper published in a medical journal which contains information about the lethal effects of ball lightning on the human body. This paper also contains information about burns of other sufferers injured by the same ball lightning and a general analysis of some problems related to the danger of ball lightning. The accident described in [52] was also described in the literature in English [31,49].

An accident in which ball lightning caused 23 human casualties, three of which were deaths (two women were found dead and one woman died in hospital) is described in $[44,57]$. The accident happened in the USSR in 1983 [44,57]. Several other accidents showing the lethal effects of ball lightning on humans and animals can be found in $[47,49,55]$ and bibliographies therein.

\subsection{Possibility of Ionizing Radiation from Ball Lightning}

The direct effects of contact with ball lightning have been shown to be hazardous in terms of injury or death to humans. Recently, a review of accidents associated with the effects of ball lightning on airplanes was published by Bychkov and Nikitin [49]. In particular, they describe several situations in which pilots of military jet airplanes bailed out because of ball lightning [49]. In addition to the hazards of direct contact, ball lightning may produce ionizing radiation, which can include X-rays and gamma-rays as well as UV radiation. Carpenter [58] was probably the first to discuss the hypothesis that ionizing radiation from ball lightning can be hazardous.

The most convincing non-biological evidence that ball lightning can produce at least short-wave UV radiation came from an incident and subsequent experiments by one of the authors [59]. While seated in her car in her driveway in rural New York State, a woman saw ball lightning hover in front of the glass front door of her house. While the ball lightning itself emitted a blue light, the glass in the front door fluoresced a different color over an 
area several times that of the nearby ball lightning object. Subsequent investigation of the glass in the door revealed that it was capable of fluorescing green under the influence of shortwave UV radiation, with the possibility that it can also fluoresce under the influence of X-rays, although that possibility was not verified experimentally. At a minimum, this investigation showed that ball lightning can emit ionizing radiation sufficiently intense to excite visible fluorescence in nearby objects.

In 1965, Dmitriev [60], accompanied by gas-sampling containers with organic material containing tritium, a gamma-ray scintillometer, and a transistor radio, witnessed ball lightning appear above a river and come ashore during a time span of nearly a minute. He was able to capture gas samples from the visible trail of the object, and subsequent tests revealed high concentrations of ozone and oxides of nitrogen. Additionally, the transistor radio emitted a high level of noise during the passage of the ball lightning, and the scintillometer registered a significant dose rate at a distance of about $2 \mathrm{~m}$ from the ball lightning, although this reading may have been spurious due to radio-frequency interference with the instrument's electronics, and the exact registered dose rate is unclear due to an erratum in either the original Russian version of [60] or its English version, where the values of 1.2 millirads per hour and 1.2 megarads per hour, respectively, are presented. Nevertheless, this incident remains the only time when ball lightning was known to be in the vicinity of gamma-ray instrumentation, and is at least suggestive that ball lightning produces such radiation.

Assumptions about the radiation hazard of some ball lightning is in agreement with several other reports about physical and biological effects that were or could be caused by ball lightning (see, e.g., [24,28,31,55,56] and bibliographies therein). For example, Garfield [56] considered an accident described by Cowgill [61] as associated with ball lightning. The accident happened near Maracaibo, Venezuela, in 1886 and resulted, in particular, in violent vomiting and the formation of black blotches on the skin of the sufferers. The sufferers did not report an observation of a fiery ball or similar object, but this fact does not contradict the assumption that they were injured by ball lightning, because it is possible that they could not see the object due to its dazzling light or for some other reason [30,55]. Stakhanov [47] mentioned a letter informing him, in particular, about the loss of hair and teeth after the passage of ball lightning near the author of the letter, but doubted its truth. These and several other reports can be explained within the framework of the ball lightning model proposed in [55]. The model is based on the assumption that ball lightning has a core consisting of clouds of electrons and almost totally ionized ions which oscillate with respect to each other [55]. The core has similarity to plasma clouds arising due to nuclear explosion in the atmosphere, in some of the experiments on directdrive laser thermonuclear fusion, etc., $[55,62]$. The maximum volume density $\varrho_{E}$ of ball lightning energy is about $1 \mathrm{~kJ} / \mathrm{cm}^{3}$ [55]. The radiation hazard from ball lightning with such a large $\varrho_{\mathrm{E}}$ is very high, but a situation in which even the initial value of $\varrho_{\mathrm{E}}$ is rather low, for example, of the order of $1 \mathrm{~J} / \mathrm{cm}^{3}$, is also possible $[55,62]$. In the latter situation, the predicted radiation hazard of ball lightning with sufficiently small size is low, but direct contact even with such ball lightning is highly undesirable due to the possibility of the generation of an electric pulse with energy sufficient to be lethal [55].

The expected radiation hazard of ball lightning is related to both biological effects and the possibility of malfunctioning of electronic and electric equipment [55]. It should be emphasized that according to several reports, ball lightning sometimes turns on or turns off electric equipment, for example, incandescent lamps [63,64].

\subsection{Examples of Possible Connection Between Ball Lightning and Gamma-Ray Glows}

On 13 January 2012, the Gamma-Ray Observation of Winter Thunderclouds (GROWTH) experiment, located in the Kashiwazaki-Kariwa nuclear power plant in Niigata prefecture, Japan, recorded a gamma-ray flash with a duration less than $300 \mathrm{~ms}$, followed by a prolonged emission lasting for about $1 \mathrm{~min}$ [23]. It has been shown that this prolonged emission could be emitted by ball lightning and generated by the annihilation of positrons emitted 
by the $\beta^{+}$-active isotopes, created by the initial gamma-ray flash, and produced by photons from ball lightning [24] (the contribution of ball lightning to the emission can be considered as a gamma-ray glow). The ball lightning model proposed in [55] and the observational data on the production of the $\beta^{+}$-active isotopes from [25] were used. The scattering of photons from ball lightning in the air and the production of electron-positron pairs in the air and the concrete roof of the building on which the detector of the radiation was placed have been taken into account [24]. Several parameters of the spectra of the prolonged emission have been explained assuming that the ball lightning had a visible radius of about 10-12 cm, and arose at an altitude of about $2.2 \mathrm{~km}$ and a horizontal distance of about $150-450 \mathrm{~m}$ from the detector [24]. A search for visible radiation from ball lightning in the GROWTH experiment and other experiments devoted to a search for high-energy photons of atmospheric origin was proposed [24].

On 1 September 2019, Aragats Space Environmental Center (ASEC), Armenia, detected visible light from several sources, appearing and disappearing during the observation, and, simultaneously, an increase in the gamma-ray count rate [20]. Visible light was detected by one camera [20]. Thus, establishing locations and typical sizes of the visible light sources was impossible. The time of registration of visible light and gamma-rays was about $15 \mathrm{~min}$ [20]. According to one of the proposed interpretations of these observational data, the visible light and gamma-rays were emitted by a swarm of ball lightning [28]. Several examples of possible sets of the distance between ball lightning and the detector of gamma-rays (plastic scintillator) and ball lightning parameters have been presented. These examples correspond to distances of $2-5 \mathrm{~km}$ and a ball lightning core radius of about $4-23 \mathrm{~cm}[28]$.

It is worth noting that other interpretations of the aforementioned observational data were also proposed in $[20,23]$ and the physical nature of the sources of the prolonged gamma-ray emissions seems to remain unestablished.

\section{Conclusions}

The discovery of high-energy physics that occur in thunderstorms raises the possibility that unforeseen radiation hazards may be present to both aircraft personnel and equipment in the vicinity of thunderstorms. The effect of TGFs on avionics is most likely to be in the form of an unexplained and possibly catastrophic multiple-site failure of radiation-sensitive electronics such as SRAMs. Depending on the severity of the failures, such an incident might pass almost unnoticed or could lead to serious adverse consequences to an aircraft's flightworthiness. It is possible that records of such incidents exist without explanation, and the investigation of airline maintenance and incident records might uncover a situation which could be explained by irradiation from neutron-producing TGFs.

Regarding hazards to humans, the probability that enough radiation to cause prompt ill effects to be received by aircraft personnel in a single incident of irradiation by a TGF beam or the high-energy photons generated by positive leader strike is very low. Nevertheless, the radiation dose that such an incident could cause would add significantly to the already-known radiation hazards that airline crews encounter because of the large amounts of time they spend at altitudes which do not shield them as much from cosmic rays as residence at or near sea level does, due to the increased depth of the atmosphere at lower altitudes. At a minimum, investigations of ambient radiation levels in commercial aircraft should be undertaken on a long-term basis to provide quantitative observational data which could either confirm or render questionable the possibility that TGFs can produce harmful amounts of radiation within aircraft.

As for the hazards posed to air travelers by ball lightning, the rarity of sightings of the phenomenon compared to those of ordinary lightning means that incidents of ball lightning actually on board aircraft are so unusual as to be remarkable. Nevertheless, they have been known to occur, and prudence would dictate one's prompt removal from the immediate vicinity of a ball lightning object on an aircraft if at all possible, both from the viewpoint of avoiding immediate injury and because of possible radiation hazards. The nature of 
gamma-ray glows and their possible connection with ball lightning remains unknown, but if ball lightning does emit gamma-rays or X-rays, it should be considered as a possible candidate for the source of such glows, and as a source of hazardous radiation for aircraft as well. It is possible that the registration of parameters of fluxes of high-energy photons of atmospheric origin, especially in situations when visible light is also detected, and detailed studies of the health problems of patients influenced by ball lightning, including those influenced many years ago, will provide the final answer on the question about the reality of the radiation hazard of ball lightning.

Author Contributions: K.D.S. researched and wrote portions of Sections 1-3. M.L.S. wrote Sections 4 and 5 and researched additional material for the entire paper. Both authors have read and agreed to the published version of the manuscript.

Funding: This research was partially funded by the Julian Schwinger Foundation under grant JSF-16-04-0000 to K.S.

Conflicts of Interest: The authors declare no conflict of interest.

\section{References}

1. Gravelle, C.M.; Stano, G.; Carcione, B.C.; Elsenheimer, C.B. Utilizing the Geostationary Lightning Mapper Long-Flash Detection Capability for National Weather Service Decision Support Services. In Proceedings of the American Meteorological Society 2019 Annual Conference, Phoenix, Arizona, 9 January 2019; Talk 7.3. Available online: https://ams.confex.com/ams/2019Annual/ meetingapp.cgi/Paper/354282 (accessed on 28 June 2021).

2. Wilson, C.T.R. The acceleration of beta particles in strong electric fields such as those in thunderclouds. Math. Proc. Camb. Philos. Soc. 1925, 22, 534-538. [CrossRef]

3. Rakov, V.A.; Uman, M.A. Lightning Physics and Effects; Cambridge University Press: Cambridge, UK, 2003.

4. Torii, T.; Takeishi, M.; Honoso, T. Observation of gamma-ray dose increase associated with winter thunderstorm and lightning activity. J. Geophys. Res. 2002, 107, 4324:1-4324:9. [CrossRef]

5. Dwyer, J.; Smith, D.M.; Cummer, S.A. High-energy atmospheric physics: Terrestrial gamma-ray flashes and related phenomena. Space Sci. Rev. 2012, 173, 133-196. [CrossRef]

6. Parks, G.K.; Mauk, B.H.; Spiger, R.; Chin, J. X-ray enhancement detected during thunderstorm and lightning activities. Geophys. Res. Lett. 1981, 8, 1176-1179. [CrossRef]

7. McCarthy, M.; Parks, G.K. Further observations of X rays inside thunderstorms. Geophys. Res. Lett. 1985, 12, 393-396. [CrossRef]

8. Moore, C.B.; Eack, K.B.; Aulich, G.D.; Rison, W. Energetic radiation associated with lightning stepped-leaders. Geophys. Res. Lett. 2001, 28, 2141-2144. [CrossRef]

9. Dwyer, J.R.; Uman, M.A.; Rassoul, H.A.; Al-Dayeh, M.; Caraway, L.; Jerauld, J.; Rakov, V.A.; Jordan, D.M.; Rambo, K.J.; Corbin, V.; et al. Energetic radiation produced during rocket-triggered lightning. Science 2003, 299, 694-697. [CrossRef]

10. Fishman, G.J.; Bhat, P.N.; Mallozzi, R.; Horack, J.M.; Koshut, T.; Kouvelioutou, C.; Pendleton, G.N.; Meegan, C.A.; Wilson, R.B.; Pacieas, W.S.; et al. Discovery of intense gamma-ray flashes of atmospheric origin. Science 1994, 264, 1313-1316. [CrossRef] [PubMed]

11. Tavani, M.; Argan, A.; Paccagnella, A.; Pesoli, A.; Palma, F.; Gerardin, S.; Bagatin, M.; Trois, A.; Picozza, P.; Benvenuti, P.; et al. Possible effects on avionics induced by terrestrial gamma-ray flashes. Nat. Hazards Earth Syst. Sci. 2013, 13, 1127-1133. [CrossRef]

12. Smith, D.M.; Dwyer, J.R.; Hazelton, B.J.; Grefenstette, B.W.; Martinez-McKinney, G.F.M.; Zhang, Z.Y.; Lowell, A.W.; Kelley, N.A.; Splitt, M.E.; Lazarus, S.M.; et al. The rarity of terrestrial gamma-ray flashes. Geophys Res. Lett. 2011, 38, L08807:1-L08807:5. [CrossRef]

13. Dwyer, J.; Uman, M.A. The physics of lightning. Phys. Reports. 2014, 534, 147-241. [CrossRef]

14. Dwyer, J.R.; Smith, D.M.; Hazelton, B.J.; Crefenstette, B.W.; Kelley, N.A.; Lowell, A.W.; Schaal, M.M.; Rassoul, H.K. Positron clouds within thunderstorms. J. Plasma Phys. 2015, 81, 475810405:1-475810405:17. [CrossRef]

15. Wada, Y.; Bowers, G.S.; Enoto, T.; Kamogawa, M.; Nakamura, Y.; Morimoto, T.; Smith, D.M.; Furuta, Y.; Nakazawa, K.; Yuasa, N.; et al. Termination of electron acceleration in thundercloud by intracloud/intercloud discharge. Geophys. Res. Lett. 2018, 45, 5700-5707. [CrossRef]

16. Yuasa, T.; Wada, Y.; Enoto, T.; Furuta, Y.; Tsuchiya, H.; Hisadomi, Sh.; Tsuji, Y.; Okuda, K.; Matsumoto, T.; Nakazawa, K.; et al. Thundercloud Project: Exploring high-energy phenomena in thundercloud and lightning. Prog. Theor. Exp. Phys. 2020, 2020, 103H01:1-103H01:27. [CrossRef]

17. Gibney, E. Mystery gamma rays could help solve age-old lightning puzzle. Nature 2021, 590, 378-381. [CrossRef]

18. Diniz, G.S.; Ferreira, I.S.; Wada, Y.; Enoto, T. Generation possibility of gamma-ray glows induced by photonuclear reactions. Geophys. Res. Atmos. 2021. Available online: https://onlinelibrary.wiley.com/doi/10.1029/2020JD034101 (accessed on 12 May 2021). 
19. Chilingarian, A.; Mkrtchyan, H. Role of the lower positive charge region (LPCR) in initiation of the thunderstorm ground enhancements (TGEs). Phys. Rev. D 2012, 86, 072003:1-072003:11. [CrossRef]

20. Chilingarian, A.; Hovsepyan, G.; Elbekian, A.; Karapetyan, T.; Kozliner, L.; Martoian, H.; Sargsyan, B. Origin of enhanced gamma radiation in thunderclouds. Phys. Rev. Res. 2019, 1, 033167:1-033167:9. [CrossRef]

21. Brunetti, M.; Secchini, S.; Galli, M.; Giovannini, G.; Pagliarin, A. Gamma-ray bursts of atmospheric origin in the MeV energy range. Geophys. Res. Lett. 2000, 27, 1599-1602. [CrossRef]

22. Shmatov, M.L. Expected spectrum of high-energy photons from ball lightning. J. Plasma Phys. 2006, 72, 277-284. [CrossRef]

23. Umemoto, D.; Tsuchiya, H.; Enoto, T.; Yamada, S.; Yuasa, T.; Kawaharada, M.; Kitaguchi, T.; Nakazawa, K.; Kokubun, M.; Kato, H.; et al. On-ground detection of an electron-positron annihilation line from thunderclouds. Phys. Rev. E 2016, 93, 021201. [CrossRef]

24. Shmatov, M.L. Possible detection of high-energy photons from ball lightning. Phys. Rev. E 2019, 99, 043203:1-043203:6. [CrossRef]

25. Enoto, T.; Wada, T.; Furuta, Y.; Nakazawa, K.; Yuasa, T.; Okuda, K.; Makishima, K.; Sato, M.; Nakano, T.; Umemoto, D.; et al. Photonuclear reactions triggered by lightning discharge. Nature 2017, 551, 481-484. [CrossRef] [PubMed]

26. Chum, J.; Langer, R.; Baše, J.; Kollárik, M.; Strhárský, I.; Diendorfer, G.; Rusz, J. Significant enhancement of secondary cosmic rays and electric field at the high mountain peak of Lomnický Štít in High Tatras during thunderstorms. EarthPlanets Space 2020, 72, 28:1-28:20. [CrossRef]

27. Chilingarian, A. High energy physics in the Earth's atmosphere. Priroda 2021, 3, 11-25.

28. Shmatov, M.L. Possible detection of visible light and $\gamma$ rays from a swarm of ball lightning. Phys Rev. E 2020, 102, 013208:1-013208:6. [CrossRef] [PubMed]

29. Rutjes, C.; Diniz, G.; Ferreira, I.S.; Ebert, U. TGF afterglows: A new radiation mechanism from thunderstorms. Geophys. Res. Lett. 2017, 44, 10702-10712. [CrossRef]

30. Shmatov, M.L. Possible scenarios for the initial acceleration of electrons of the core of ball lightning. J. Plasma Phys. 2015, 81, 905810607:1-905810607:13. [CrossRef]

31. Shmatov, M.L.; Stephan, K.D. Advances in ball lightning research. J. Atmos. Sol. Terr. Phys. 2019, 195, 105115:1-105115:17. [CrossRef]

32. Dwyer, J.R. Implications of x-ray emission from lightning. Geophys Res. Lett. 2004, 31, L12102:1-L12102:4. [CrossRef]

33. Tavani, M.; Marisaldi, M.; Labanti, C.; Fuschino, F.; Agran, A.; Trois, A.; Giommi, P.; Colafrancesco, S.; Pittori, C.; Palma, F.; et al. Terrestrial gamma-ray flashes as powerful particle accelerators. Phys. Rev. Lett. 2011, 106, 018501:1-018501:5. [CrossRef]

34. Xu, W.; Celestin, S.; Pasko, V.P. Source altitudes of terrestrial gamma-ray flashes produced by lightning leaders. Geophys. Res. Lett. 2012, 39, L08801:1-L08801:5. [CrossRef]

35. Celestin, S.; Wu, W.; Pasko, V.P. Terrestrial gamma ray flashes with energies up to $100 \mathrm{MeV}$ produced by nonequilibrium acceleration of electrons in lightning. J. Geophys. Res. 2012, 117, A05315:1-A05315:9. [CrossRef]

36. Shmatov, M.L. New model of initial acceleration of electrons of terrestrial gamma-ray flashes with a hard spectrum. Phys. Lett. A. 2015, 379, 1358-1360. [CrossRef]

37. Gurevich, A.V. On the theory of runaway electrons. ZhETF 1960, 39, 1296-1308.

38. Babich, L.P. High-Energy Phenomena in Electric Discharges on Dense Gases: Theory, Experiment and Natural Phenomena; Futureplast: Arlington, VA, USA, 2003.

39. Kutsyk, I.M.; Babich, L.P.; Donskoii, E.N. Self-sustained relativistic-runaway-electron avalanches in the transverse field of lightning leader as sources of terrestrial gamma-ray flashes. Pis'ma V ZhETF 2011, 94, 647-650. [CrossRef]

40. Dwyer, J.; Smith, D.M.; Uman, M.A.; Saleh, Z.; Grefenstette, B.; Hazelton, B.; Rassoul, H.K. Estimation of the fluence of highenergy electron bursts produced by thunderclouds and the resulting radiation doses received in aircraft. J. Geophys. Res. D 2010, 115, D09206:1-D09206:10. [CrossRef]

41. Meier, M.M.; Copeland, K.; Klöble, K.E.J.; Matthiä, D.; Plettenberg, M.C.; Schennetten, K.; Wirtz, M.; Helleg, Ch. E. Radiation in the atmosphere-A hazard to aviation safety? Atmosphere 2020, 11, 1358:1-1358:31. [CrossRef]

42. Makowski, D.; Grecki, M.; Mukherjee, B.; Simrock, S.; Swiercz, B.; Napieralski, A. The application of a SRAM chip as a novel neutron detector. J. Exp. Nanosci. 2006, 1, 261-268. [CrossRef]

43. Abrahamson, J.; Bychkov, A.V.; Bychkov, V.L. Recently reported sightings of ball lightning: Observations collected by correspondence and Russian and Ukranian sightings. Phil. Trans. Roy. Soc. Lond. A 2002, 360, 11-35. [CrossRef] [PubMed]

44. Smirnov, B.M. The properties and the nature of ball lightning. Phys. Rep. 1987, 152, 177-236. [CrossRef]

45. Stenhoff, M. Ball Lightning: An Unsolved Problem in Atmospheric Physics; Kluwer/Plenum Press: New York, NY, USA, 1999.

46. Barry, J.D. Ball Lightning and Bead Lightning: Extreme Forms of Atmospheric Electricity; Plenum Press: New York, NY, USA; London, $\mathrm{UK}, 1980$.

47. Stakhanov, I.P. About the Physical Nature of Ball Lightning, 3rd ed.; Nauchnyi Mir: Moscow, Russia, 1996.

48. Boerner, H. Ball Lightning: A Popular Guide to a Longstanding Mystery in Atmospheric Electricity; Springer: Cham, Switzerland, 2019.

49. Bychkov, V.L.; Nikitin, A.I. Ball lightning: A new step in understanding. In The Atmosphere and Ionosphere: Elementary Processes, Monitoring, and Ball Lightning Physics of Earth and Space Environments; Springer: Heidelberg, Germany, 2014; pp. 201-367.

50. Selvaggi, G.; Monstrey, S.; von Heimburg, D.; Hamdi, M.; Van Landuyt, K.; Blondeel, P. Ball lightning burn. Annals Plastic Surg. 2003, 50, 541-544. [CrossRef] 
51. García, M.A.C.; Tovilla, Y.M.; Barreto, C.A.J.; Robles, J.J.S.; Lorenzo, I.E.G. Burn by ball lightning. Case report. Rev. Pediatr. Aten. Primaria. 2018, 20, 157-161.

52. Dmitriev, M.T.; Lakshin, A.M.; Morozov, S.S. Specific features of injuries by ball lightning. Ortop. Travmatol. Protez. 1986, 11, 66-67.

53. Cohen, M.A. Clinical peals: Struck by lightning. Acad. Emerg. Med. 2001, 8, 929-931. [CrossRef]

54. Cherington, M.; Yarnell, P.R. Ball lightning encephalopathy. J. Burn Care Rehabil. 2003, 24, 175. [CrossRef] [PubMed]

55. Shmatov, M.L. New model and estimation of the danger of ball lightning. J. Plasma Phys. 2003, 69, 507-527. [CrossRef]

56. Garfield, E. When citation analysis strikes ball lightning. Essays Inf. Sci. 1976, 2, 479-490.

57. Bocharov, G. Drama in a valley. Lit. Gaz. 1983, 51, 12.

58. Carpenter, D.G. Plasma Theory Applied to Ball Lightning. Ph.D. Thesis, Iowa State University of Science and Technology, Ames, IA, USA, 1962.

59. Stephan, K.D.; Krajcik, R.; Martin, R.J. Fluorescence caused by ionizing radiation from ball lightning: Observation and quantitative analysis. J. Atmos. Sol. Terr. Phys. 2016, 148, 32-38. [CrossRef]

60. Dmitriev, M.T. Stability mechanism for ball lightning. ZhTF 1969, 39, 387-394.

61. Cowgill, W. Curious phenomenon in Venezuela. Sci. Am. 1886, 55, 389.

62. Shmatov, M.L. Ball lightning with the nonrelativistic electrons of the core. J. Plasma Phys. 2015, 81, 905810406:1-905810406:19. [CrossRef]

63. Brand, W. Der Kugelblitz; Grand: Hamburg, Germany, 1923.

64. Imyanitov, I.; Tikhii, D. Za Gran'yu Zakona (Outside the Verge of Law); Gidrometeoizdat: Leningrad, USSR, 1967. 